\title{
A DIFFERENTIATED DIDACTIC APPROACH TO TEACHING THE ARTS (D.D.A.T.A.) FOR THE PURPOSES OF SPECIAL EDUCATION AND TRAINING
}

\author{
Ioannis Makris \\ High School of Pedagogical and Technical Education, Greece
}

\begin{abstract}
The goal of the present work is to present the key of pedagogical and didactical principles involved in the differentiated teaching of such arts as music and dance for the purposes of Special Education and Training (Makris, 2019). The paper also will link that differentiated approach with Positive Psychology and, more specifically, with the P.E.R.M.A. model developed by Positive Psychology founder M. Seligman (Slavin, Schindler et al., 2012); and with M. Apter's Reversal Theory (Makris, 2009).

At this presentation, we will be presenting didactical principles, methodological tools and case studies deriving from our clinical work that we carried out for 7 years (2012-2019) with mentally challenged individuals (Makris, 2019). In this study also we will have the chance to focus in teamwork teaching so that we may comprehend the principles of that approach experientially. What is more, this work will also focus on potential fields offering themselves for future academic research.
\end{abstract}

Keywords: differentiated teaching, Special Education Training, teamwork teaching, didactics of arts.

\section{Introduction}

Teaching individuals with mental disabilities is a task fraught with difficulties (Vilkeliene, Makris, Ingelevicius, Papatherapontos, \& Sokolosky, 2017a,b). Two are the reasons that give rise to those obstacles: the first reason entails the extent and kind of mental disability that a learner may have (Macri \& Makris, 2014a). The second one involves the very personality of the learners themselves herself (Macri \& Makris, 2014b). Thus, when it comes to mental disability, teachers are called upon to work with individuals who possess different abilities and skills, various degrees of readiness, a varied pace of work and learning, a number of learning profiles, not to mention that a learner with mental disabilities may be interested in different things and have different talents than the other mentally disabled learners (Macri \& Makris, 2014c).

Differentiating the teaching process is a proposal which, on its very own, stumbles onto social justice. To cite Aristotle, "there is nothing more unequal than 
the equal treatment of unequal people". Be that as it may, if we wish to be effective, especially when teaching the mentally disabled, we must be in a position to detect our learners' individual traits, particularities, needs, and skills (cognitive, emotional, kinetic, communication, social, relaxation, and recreational) (Macri, Makris et al., 2019).

The aim of the present article is to present a modern teaching approach and more specifically the key principles governing the Differentiated Didactic Approach to Teaching the Arts (D.D.A.T.A) in the field of Special Education. That approach (our methodology) emerged over time through not only the collection of empirical measurements but also through the seven-year period of teaching approximately 100 mentally disabled individuals. It was within that framework and within the framework of developing inclusive didactics that we also formed a musical ensemble which has given numerous concerts and performances throughout the years, collaborating in Greece with both amateur and professional choirs (Makris, 2019). As the article goes on, we will be examining at which points and how D.D.A.T.A. is linked to positive psychology and, more specifically, to Seligman’s P.E.R.M.A. model and M. Apter's Reversal Theory.

\section{Methodology}

When teaching music or dance and before beginning work with a specific learner, we need to be in possession of that learner's medical, work therapy, and social evaluations (Makris \& Macri, 2003). Moreover, the profile of that learner must be clear-cut in our mind. The arts and music in particular are a stand-alone, specific, and quite specialized field (Mullet, Morales, Guadalupe, Makris, Roge, \& Munoz, 2012). Thus, in order to implement D.D.A.T.A., and following our first contact with mentally disabled learners, we need to be in a position to answer in detail the following Pedagogical Report (PR) questions regarding those learners:

(1) What interests do they have?

(2) What are their talents/aptitudes?

(3) What tasks can they perform?

(4) What knowledge do they have?

(5) Which are the auxiliary tools that will assist them best in their tasks?

(6) What are their individual learning profiles?

(7) How do they prefer to work?

(8) In what state of readiness are they?

(9) What is their pace when engaged in a task? (Macri, Makris et al., 2019). 


\section{The Differentiated Didactic Approach to Teaching the Arts (D.D.A.T.A)}

The D.D.A.T.A. model is a model we have successfully applied for the last 7 years (2013- present) within the framework of our teaching music to mentally disabled individuals (Makris, 2015b). What is more, we discovered that the D.D.A.T.A. model has also proved successful in the teaching of dance. Thus, on the basis of our clinical experience and the empirical measurements we carried out throughout the period 2013-present, we can safely present some of the key facts that corroborate the D.D.A.T.A. model's effectiveness and stem from the model's empowering effects:

(A) successful implementation of team work on music (orchestra) and dance (group choreography) leading to:

(1) ambience of enthusiasm;

(2) supportive climate on an individual basis;

(3) clear perception by the mentally disabled individual of other members in the group;

(4) crystal-clear goals that can be adjusted to individual needs;

(5) clear-cut roles;

(6) delegation of duties depending on individual abilities/skills;

(7) uniting people possessing skills of varying degrees;

(8) a positive attitude towards learning; and

(9) an increase in self-esteem and self-confidence.

(B) Selection of the right repertory appropriately adjusted to the needs of learners with mental disabilities participating in an orchestra or dance ensemble.

(C) A positive psychological climate where we observe the application of Seligman's P.E.R.M.A. model applies across the board.

(D) Appropriate motivation, with teachers taking well into account the fact that implementation of such motivation necessitates solid knowledge of the motivational theory as discussed in Apter's Reversal Theory.

(E) Centrally-controlled guidance of the learner group via the "Makris" Pedal Switch Visual Signal Generator that our team has constructed (Makris, 2015a,b).

(F) Precise analysis and appropriate codification of the parameters involving music, in the case of an orchestra, or involving choreographed movement, in the case of a dance group.

(G) Collaboration with amateur and professional choirs within the framework of pedagogical inclusion (Makris, 2019). 
Makris, 2020. Differentiated Didactic Approach to Teaching the Arts (D.D.A.T.A.) for the Purposes of Special Education and Training

The axes on which a teacher should move when applying the D.D.A.T.A. model (Makris, 2019) are:

- $\quad$ Pinpointing the interests of each learner.

- $\quad$ Pinpointing the degree of under-performance of a learner per field of skills.

- $\quad$ Selection of the works to be taught.

- Creating the appropriate psychological ambience and encouraging each learner accordingly.

- $\quad$ Breakdown of the project into factors (Makris \& Mullet, 2003).

- $\quad$ Visualizing the factors (Makris, 2017).

- $\quad$ Codifying the factors

- Determining the steps of the project

- Adjusting and differentiating the project to the level of each learner.

- Demonstrating the way the tasks should be performed; the strategies involved; and modelizing.

- $\quad$ Taking advantage of the positive potential per field of skills.

- Helping learners develop their artistic perception and skills.

- $\quad$ Ongoing, differentiated readjustment of goals, and ongoing evaluation.

\section{Employing music and dance for the purposes of special education}

Gestalt psychology emphasizes that the whole of anything is greater than its parts. It also offers the premise that learning includes the inception of a structural whole which, created by individual elements, is no mere mechanical reaction to a stimulus. The cases of an orchestra and group choreography function in precisely that way. What we have is a structural whole, be it a musical work or choreography, which is the result of numerous individual elements. It is exactly those individual elements that teachers must work on so that they may arrive at a teaching process which becomes effective through differentiation.

In the case of an orchestra, the individual parts of the "whole" are the musicians who play different musical instruments and, needless to say, the factors into which music can be analyzed: melody, rhythm, timbre, and tonality. In a like manner, the individual parts of a group choreography are the dancers who perform in the group, together with all the factors relating to dance: direction, level, movement, timing, rhythm, weight, flow. 


\section{Case study: D.D.A.T.A. and the Ichochroma (Timbre) Orchestra}

The D.D.A.T.A. model took shape within the framework of the clinical work of Dr. Ioannis Makris at "Ergastiri", a workshop stewarded by the Association of Parents and Guardians of Persons with Disabilities, Athens, Greece (Macri, Makris et al., 2019). The preliminary, empirical observations on 100 individuals with mental disabilities of over $67 \%$ enabled the formation of the "Makris" standards and methodology. In turn, the "Makris" methodology generated a series of logical hypotheses which created the scientific premises of a broader theoretical framework whose confirmation is constantly renewed through successive empirical measurements (Makris, 2019). Moreover, that D.D.A.T.A. framework enables us to interpret and predict the appearance of various situations at the work level.

The Ichochroma Orchestra is comprised of people with mental disabilities and is the ultimate vehicle for the practice of differentiated teaching. Its approximately twenty-five members have given a number of concerts in collaboration with amateur and professional choirs (Makris, 2019). In July 2019, the Ichochroma Orchestra participated in an international music festival, in tandem with the choir of the city hosting the event. The differentiation we implement through D.D.A.T.A. functions at the pedagogical as well as the organizational level.

\section{Differentiations at the pedagogical level:}

$>$ Content and materials are both differentiated. We select the appropriate repertory for the specific group we are working with. Wherever and whenever necessary, we make changes in the musical instruments' tonality and tuning such as the guitar and the ukulele.

$>$ The teaching process and activities are differentiated. By means of the "Makris" Pedal Switch Visual Signal Generator we can fine-tune the entire teaching process (Makris, 2015a). At this point, our goal is not so much to teach music but the right use of a musical instrument in a specific setting.

$>\quad$ We differentiate the results. There have been cases when we had to change a certain song's introduction or rhythm for the sake of simplification.

\section{Differentiations at the organizational level:}

$>$ We differentiate the environment, arranging it in such a way so as to be able to have effective rehearsals.

$>$ We differentiate the way learners sit during rehearsals so that they may all make visual contact with us but, most importantly, with the "Makris" Pedal Switch Visual Signal Generator. 
Makris, 2020. Differentiated Didactic Approach to Teaching the Arts (D.D.A.T.A.) for the Purposes of Special Education and Training

$>$ We differentiate the orchestra's lineup depending on the stage offered at each venue where the Ichochroma Orchestra is to perform.

$>$ We differentiate the way learners work. We receive from each learner that which s/he is able to give and work on that. To that purpose, we provide a greater number of instruments per category of musical instrument.

$>$ We differentiate the pace at which each learner performs her/his tasks, taking full advantage of what each learner is able to give. For example, our orchestra includes a hyperactive learner whose initial participation in the tasks set was of short duration. At present, our hyperactive learner participates in the rehearsals at the same pace as the rest of the learners.

$>$ We differentiate the classroom's climate. Each learner is unique and when some of the learners are in need of more time, more time is what we dedicate to them.

$>$ We differentiate the elements that support each learner so that her/his performance improves.

\section{D.D.A.T.A. and Seligman's P.E.R.M.A. theoretical model}

Seligman's P.E.R.M.A. model helps us fathom the elements which connect to happiness (Slavin, Schindler et al., 2012). It also helps us increase the level of some of those elements so that we can bring into our life and that of our learners' a sense of fulfillment and pleasure. The analysis that follows examines those elements in association with the D.D.A.T.A. model:

P - Positive Emotion: The empirical measurements carried out after each session on all 25 of the orchestra's members in the framework of metacognitive reflection led to the direct and undoubted realization that all 25 of our "musicians" experienced positive feelings and a sense happiness.

E - Engagement: this element has been experienced by all orchestra members. At an initial stage, a "newcomer" who joins the orchestra does not readily experience the element of engagement. However, as time goes by, the more experiences the new member gathers up from her/his participation in the orchestra, the more her/his engagement with the ensemble grows. At present, all of the Ichochroma Orchestra members show a high degree of engagement.

$\mathbf{R}$ - Relationships: our orchestra members develop relationships within and without the orchestra, i.e., not only do they develop positive relationships between and among them but they also reach out to people who are not orchestra members and who come to the concerts or attend rehearsals. Overall, our learners' experiences from and participation in the orchestra help them enormously in increasing their social and communication skills, as well as their socialization process. 
M - Meaning: That is the one element fully covered within the orchestra. For the orchestra's members, participation is an ontological state because, through the orchestra, they have found a raison d'être. Participation of individuals with mental disabilities in the orchestra urges them towards subsequent participations.

A - Accomplishments: At our instigation and within the framework of D.D.A.T.A., the orchestra's "musicians" set a series of doable goals. Implementing and accomplishing those goals gives our orchestra's members a sense of happiness and joy.

The conclusion on the empirical observations we have gathered for the past seven years from our "musicians” indicates that that Seligman's P.E.R.M.A. model and the Makris D.D.A.T.A. model are 100\% in synergy.

\section{Meeting points between D.D.A.T.A. and Apter's Reversal Theory}

Reversal theory is a theory of personality, motivation, and emotion in the field of psychology. It focuses on the dynamic qualities of normal human experience to describe how a person regularly reverses between psychological states, reflecting their motivational style, the meaning they attach to a given situation at a given time and the emotions they experience (Makris \& Mullet, 2009). The theory distinctively proposes that human experience is structurally organized into metamotivational domains, of which four have been identified. Each domain consists of a pair of opposing values or motives, so that only one of each pair can be experienced in any given moment. The primary emphasis of Reversal Theory lies in the concept of reversals -by "triggering" a reversal between states, we can change the meaning attributed to the situation. Reversals can be created by changing a situation.

We became conversant with M. Apter's Reversal Theory and used it in the framework of our post-doctoral dissertation. However, we also used it in practice while applying D.D.A.T.A. and have found it extremely useful: during the teaching process, rehearsal, or performance, learners with mental disabilities can switch domain or motive at any given moment, something that impacts negatively on the whole group. When that happens, the teacher must promptly and appropriately differentiate the teaching process so that the learner may return to the appropriate domain or motive with a view to accomplishing the task given her/him. 
The graph below depicts the structure of Apter's Reversal Theory:

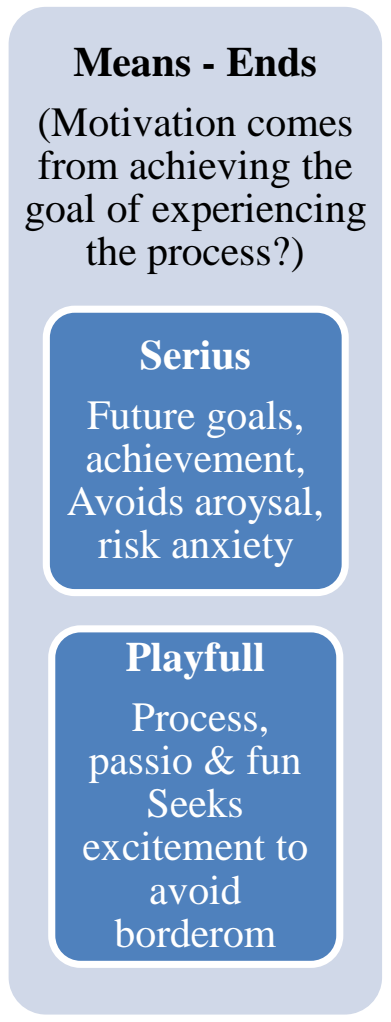

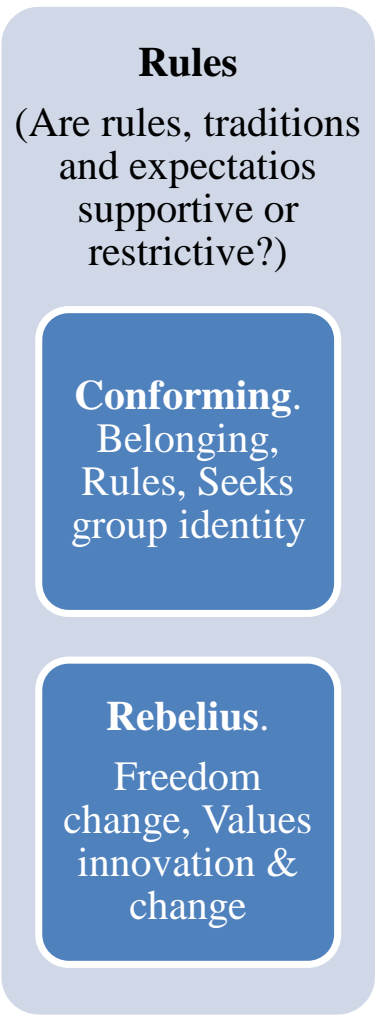

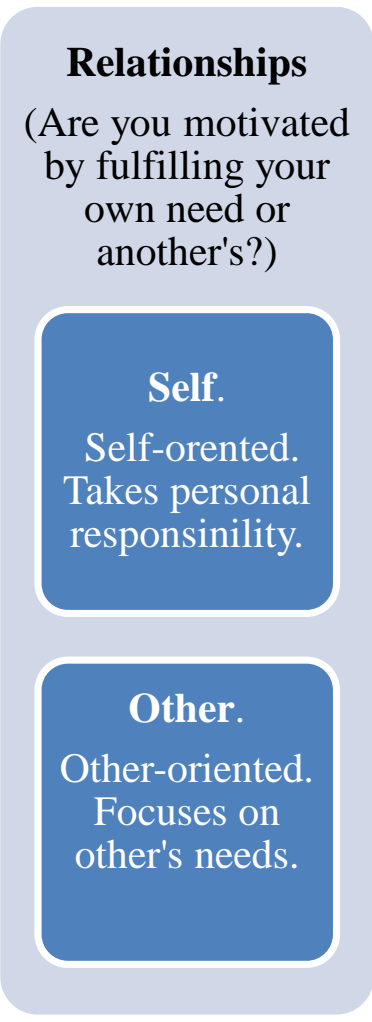

Figure 1 Apter's Reversal Theory (Makris \& Mullet, 2009)

\section{Conclusions}

While implementing the D.D.A.T.A. model we became aware of a number of mistakes that can occur during the differentiated teaching process. Below are our conclusions on some of those mistakes are:

$>$ Viewing teaching as an ordinary pedagogical process: for teachers of people with mental disabilities, teaching should not be a mere process but a get-together that is as experiential as it is creative for the teachers who also find though this differentiated teaching method an area where they can express themselves on a personal level.

$>$ Differentiated teaching of both music and dance should begin with the discovery of the core knowledge of each learner, continue with probing into the learners' skills, and move on to prioritizing and ranking goals. Last but not least, the differentiated teaching process should end with the application of corrective actions as those ensue from the ongoing evaluations. 
$>$ In brief, we also discussed the following:

$>$ The questions of the pedagogical report are crucial and teachers should be in a position to have answers to them as of the first interview with a learner.

$>$ Creating a positive psychological climate and the culture that accompanies it are both important if our aim is to render our differentiated teaching process effective.

$>$ Taking advantage of the learners' positive potential helps teachers manage the negative potential as well.

$>$ Visualization is an integral part of the D.D.A.T.A. model. Together with codification, visualization should be differentiated and adjusted to the skills each learner possesses.

$>$ Positive Psychology and the Reversal Theory find a direct field of implementation in the D.D.A.T.A. model.

$>$ In this article we presented the axes governing the pedagogical implementation of D.D.A.T.A., a model and approach we have been successfully applying for seven year in the cases of people with a degree of mental disability of over 67\%. Our approach's success has been evaluated by the audiences that have attended the Ichochroma Orchestra's performances. More importantly, within the framework of a European program, we were also able to develop our approach's pedagogical inclusion which stemmed from the synergy between the Ichochroma Orchestra and ordinary professional or amateur choirs.

\section{Discussion}

Currently, the D.D.A.T.A. model is applied by Dr. Ioannis Makris in Greece (Makris, 2019). However, it is an approach that can easily be implemented in other countries as well. We have come to the conclusion that actual research on D.D.A.T.A. should take place, research that does not rely simply on empirical observations but takes advantage of other research techniques as well. Such research would turn to the study of themes emerging from the realms of pedagogy, psychology, or the arts. Needless to say, such research would necessitate the establishment of a special technology and research workshop that would examine this special, differentiated teaching of the arts.

\section{References}

Macri, D., \& Makris, I. et al. (2019). Proceedings of the Scientific Conference of Hellenic Institute Pasteur. Text in Greek, Athens: Hellenic Institute Pasteur.

Macri, D., \& Makris, I. (2014a). Intellectual Disabilities. Evaluation \& Pedagogical Management. Case studies. Text in Greek. Athens: Ed. Macri/Makris. 
Makris, 2020. Differentiated Didactic Approach to Teaching the Arts (D.D.A.T.A.) for the Purposes of Special Education and Training

Macri, D., \& Makris, I. (2014b). Special Education Issues. (1): Behavioural Issues, (2): Students with Behavioural Problems. Text in Greek, Athens: Ed. Macri/Makris.

Macri, D., \& Makris, I. (2014c). Encouraging students to build teaching material in the context of research. Steps to design your lessons. August 26, 2017. Retrieved from http://www.diapolis.auth.gr/epimorfotiko_uliko/index.php/2014-09-06-09-18-43/201409-06-09-29-21/30-a8-makri

Makris, I., \& Mullet, E. (2009). A systematic inventory of motives for becoming an orchestra conductor: a preliminary study. Psychology of Music: Los Angeles

Makris, I. (2015a). Innovation and use of technology in Special Education. Panellenic Scientific and Educational Association of Secondary Education Revue, Erkyna, 6, 175- 181. Athens: PAPEDE.

Makris, I. (2015b). Creating a traditional orchestra for the needs of special education, International Congress Latvia - Proceedings, Rezekne: Rezekne Tehnologiju Akademija.

Makris, I. (2017). Visualisation and Verbalization in the use of Special Music Education. International Congress Latvia - Proceedings Rezekne: Rezekne Tehnologiju Akademija.

Makris, I. (2019). Bonne Pratique: Un concert “Extraordinaire”. Un défi "pour changer le regard sur le handicap”, Fishe Pedagogique, du Programme Cap Sur l'Ecole Inclusive KA2 Strategic Partnership. Oct 2, 2019. Retrieved from http://www.ecoleinclu siveeurope.eu/pdf/pdf-ressources-bp-fichespeda-module2/unconcertextraordinaire.pdf

Makris, I., \& Macri, D. (2003). Introduction in musictherapy Text in Greek. Athens: Grigoris.

Makris, I., \& Mullet, E. (2003). Judging the pleasantness of contour - rhythm-pitch-timbre, American Journal of Psychology, 116(4), 581-611.

Makris, I., \& Mullet, E. (2009). A systematic inventory of motives for becoming an orchestra conductor: A preliminary study. Psychology of Music, 37, 443-458.

Mullet, E., Morales, M., Guadalupe, E., Makris, I., Roge, B., \& Munoz, M.S. (2012). Functional Measurement: An Incredibly Flexible Tool, Psicologica: International Journal of Methodology and Experimental Psychology, 33(3), 631-654.

Vilkeliene, A., Makris, I., Ingelevicius, E., Papatherapontos, M., \& Sokolosky, T. (2017a). Teacher qualification dev/ment Programme. Vilnius: Ed. Alytus Music School.

Vilkeliene, A., Makris, I., Ingelevicius, E., Papatherapontos, M., \& Sokolosky, T. (2017b). T.E.L.L. Through Music. Method as a tool for the development of core competences of Adult Learners.Vilnius: Alytus Music School.

Slavin, S., Schindler, D. et al. (2012). PERMA: A Model for Institutional Leadership and Culture Change. Academic Medicine, 87, 1481. 